\title{
FAST MODEL FOR PHASE TRANSFORMATIONS DURING COOLING OF PRE-ANNEALED MULTIPHASE STEELS
}

\author{
DANUTA Szeliga ${ }^{1 *}$, Roman KUZIAK ${ }^{2}$, WhadysŁaW ZALECKI ${ }^{2}$, \\ Valeriy Pidvysots' Kyy ${ }^{2}$, Yuling Chang ${ }^{3}$, Wolfgang Bleck ${ }^{3}$, Daniel Bachniak ${ }^{1}$, \\ MACieJ PietrzyK ${ }^{1}$ \\ ${ }^{1}$ AGH University of Science and Technology, Mickiewicza 30, 30-059 Krakow, Poland \\ ${ }^{2}$ Eukasiewicz Research Network, Institute for Ferrous Metallurgy, K. Miarki 12, 44-100 Gliwice, Poland \\ ${ }^{3}$ RWTH Aachen University, Templergraben 55, 52062 Aachen, Germany \\ *Corresponding author: szeliga@agh.edu.pl
}

\begin{abstract}
A thorough experimental and numerical analysis of phase transformations in a selected high strength steel was the general objective of the paper. Dilatometric tests were performed for a wide range of cooling rates. Two models based on a mean field approach were considered. The first was an upgrade of the Johnson-Mehl-Avrami-Kolmogorov equation. The second model was based on the Leblond equation. Both models were identified using inverse analysis of the experimental data. Simulations of various cooling schedules were performed to validate the models. Phase compositions for these cooling schedules were determined. Following this the effect of elements' segregation during solidification of steel on the occurrence of marteniste/bainite bands was accounted for using the developed models.
\end{abstract}

Key words: CP steel, Phase transformations, mean field models

\section{INTRODUCTION}

The advanced high strength steels (AHSS) have been developed to improve the balance between strength and formability in sheet forming. Dual phase (DP) steels as one important group of AHSSs have been widely used for deep drawing applications while complex phase (CP) steels offer a wider range of good formability also for bending, stretch forming and hole expansion applications. Both DP and CP steels are the two most widely used steels in the automobile industry (Kuziak et al., 2008). The correlations between the mechanical properties and microstructure features have been intensively studied for DP steels (Thomser et al., 2009; Weiß-Borkowski et al., 2018). The microstructure of DP steel is characterized by the fine ferrite matrix with dispersed hard islands of martensite. The mechanical properties of DP steel are influenced mostly by the volume fraction of martensite, the martensite island size and the ferrite grain size. Besides, the hardness difference between the ferrite and martensite also influences the strain hardening behaviour and ductility (Vajragupta et al., 2014). This significant difference between the hard phase and soft matrix in DP steels leads to the poor local elongations and local formability, which are considered crucial in the hole expansion, stretch elongation and bending tests (Karelova et al., 2009). CP steel is characterized by the fine microstructure with a heterogeneous mixture of various types of bainite (Bhadeshia, 2001), martensite and ferrite. Compared with DP steel, the volume fraction of hard phases is higher, which leads to a higher yield strength and tensile strength. On the other hand, the hardness gradients inside the microstructure are smoother than in DP grades. In consequence, CP steels exhibit better local formability what makes them more suitable for stretch-forming (Ryde et al., 2012; Fonstein, 2015). 
During the manufacturing of DP and CP steels, it is important to achieve the desired volume fraction of phases and the size distribution of martensite/bainite in the matrix to meet the best mechanical properties. This is realized mostly by controlled cooling during the process (Maity \& Kawalla, 2011). AHSS gain their well-known improved cold formability from microstructure with unique differences in morphology, hardness and amounts of low temperature transformation products. Expectation that further improvement of steel properties can be obtained by control of the gradients of microstructure features and carbon concentration (Farivar et al., 2018) was the motivation for the present work. It was assumed in (Szeliga et al., 2019) that combining numerical simulations with experimental testing should supply data for better description of the microstructure, based on distribution functions (descriptors). However, to reach this goal a reliable prediction of phase transformations kinetics during cooling is needed. Therefore, the general objective of the paper was thorough experimental and numerical analysis of phase transformations in a selected high strength steel. The particular objective was to develop fast models describing kinetics of transformations during complex cooling schedules.

\section{EXPERIMENT}

Development of the CTT diagram and suplying the data for identification of the models was the objective of experiments. High strength steel containing $0.08 \% \mathrm{C}, 1.89 \% \mathrm{Mn}, 0.485 \% \mathrm{Si}, 0.038 \% \mathrm{Cr}, 0.13 \% \mathrm{Mo}$, $0.048 \% \mathrm{Nb}$, and $0.137 \% \mathrm{Ti}$ was investigated. The testing material was $2.5 \mathrm{~mm}$ thick hot rolled strip. Since the material was in the form of the strip, it was not possible to apply deformation at high temperatures before the dilatometric tests. Therefore, the influence of the austenitic grain size on the transformation kinetics was examined by heating the dilatometer samples to different temperatures. Thus, the samples measuring $2.5 \times 4 \times 10 \mathrm{~mm}$ were austenitized at: i) $920^{\circ} \mathrm{C}$ for $600 \mathrm{~s}$, ii) $1020^{\circ} \mathrm{C}$ for $300 \mathrm{~s}$, iii) $1000^{\circ} \mathrm{C}$ for $600 \mathrm{~s}$ and iv) $1100^{\circ} \mathrm{C}$ for $600 \mathrm{~s}$. Austenite grain size of $<5 \mu \mathrm{m}, 6.5 \mu \mathrm{m}, 6.6 \mu \mathrm{m}$ and $13.7 \mu \mathrm{m}$ was obtained for the austenitization parameters i, ii, iii and iv, respectively. Preheating temperature of $920^{\circ} \mathrm{C}$ was considered too low and microstructures after preheating according to schedules ii, iii and iv only are shown in figure 1 . The Authors are aware of the incomplete dissolution of microalloying elements in the experiments but the focus is laid on a fast model with consideration of the impact of local $\mathrm{C}$ and $\mathrm{Mn}$ distributions.
After preheating the samples were cooled to the room temperature with different constant cooling rates in the range $0.02-135^{\circ} \mathrm{C} / \mathrm{s}$.
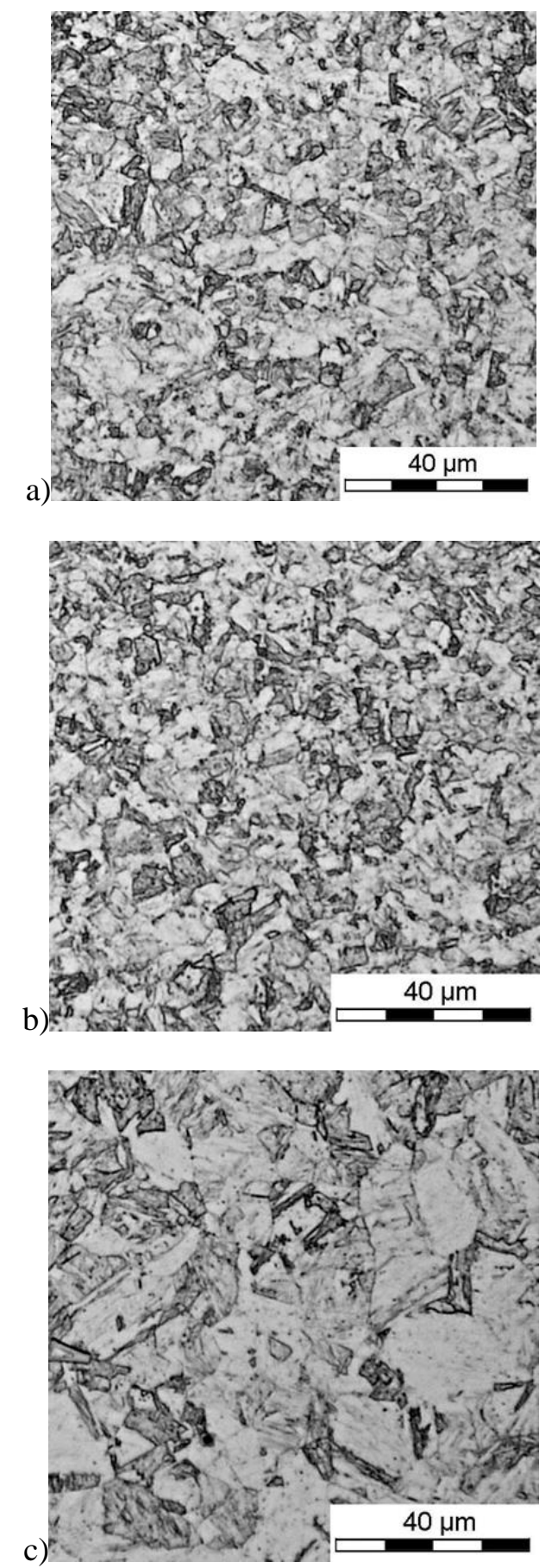

Fig. 1. Microstructure (LOM) after preheating according to schedules ii (a), iii (b) and iv (c).

After each dilatometric test the samples were subject to LOM and SEM microstructure analysis. Selected microstructures for varius cooling rates are shown in figure 2. Banded character of the microstructure is well seen in this figure. The lower is cooling rate, the banding is more evident. The bands are developed on the basis of pearlite, bainite and mar- 
tensite components. For larger cooling rate hard constituents are uniformly distributed and banding disappears.

Preheating schedules ii and iii gave similar austenite grain size, therefore, schedules i, iii and iv were further investigated. Analysis of the micrographs shows that high cooling rates are needed to obtain multiphase microstructure. Therefore, micrographs for the cooling rates of $25^{\circ} \mathrm{C} / \mathrm{s}, 50^{\circ} \mathrm{C} / \mathrm{s}$ and $135^{\circ} \mathrm{C} / \mathrm{s}$ are presented in figures 3,4 and 5 for the preheating schedules i, iii and iv, respectively.
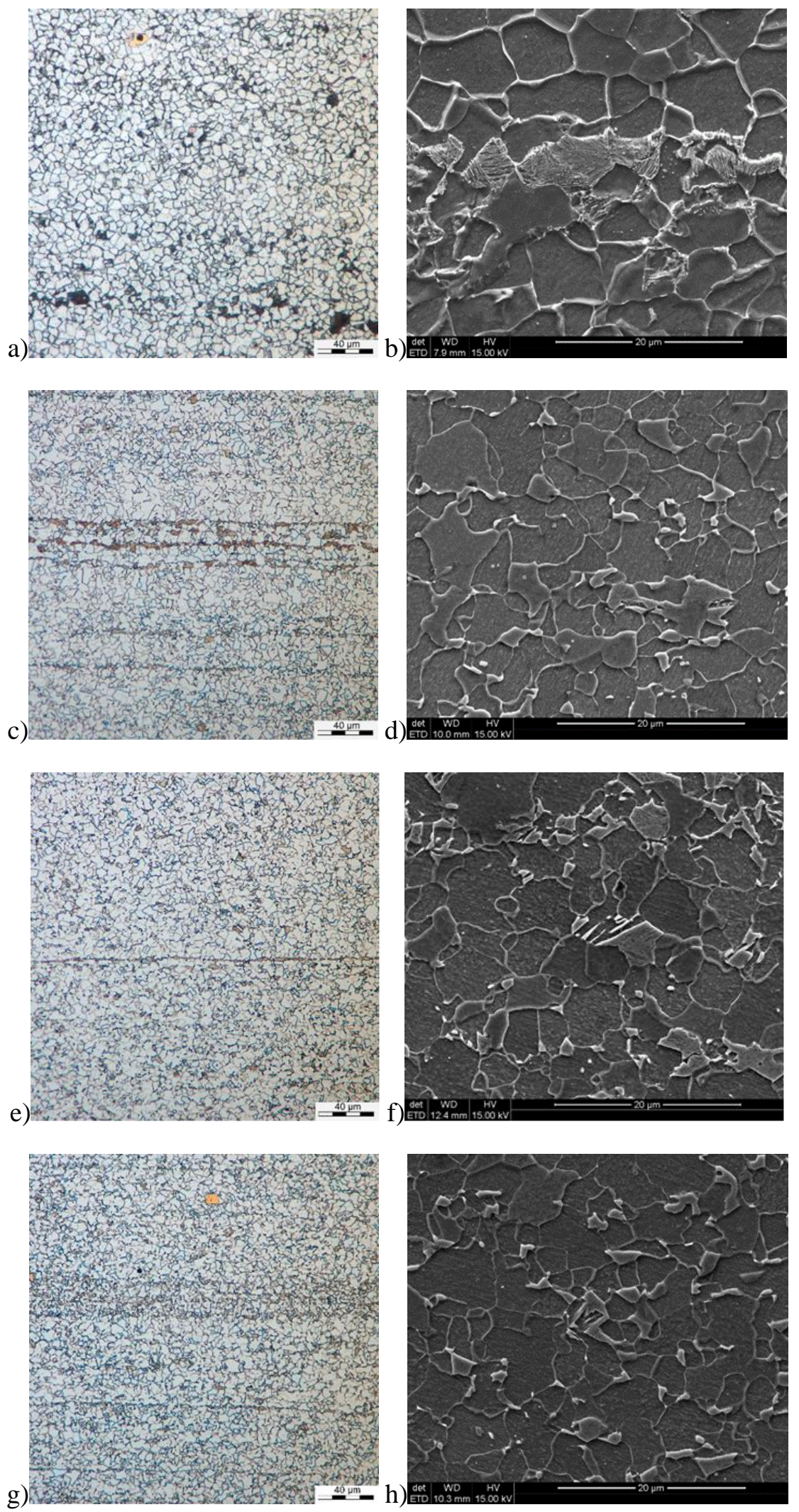

Fig. 2. $\operatorname{LOM}(a, c, e, g)$ and SEM $(b, d, f, h)$ microstructure after cooling rates of $0.02^{\circ} \mathrm{C} / \mathrm{s}(a, b), 1^{\circ} \mathrm{C} / \mathrm{s}(c, d), 10^{\circ} \mathrm{C} / \mathrm{s}(e, f)$ and $15^{\circ} \mathrm{C} / \mathrm{s}(\mathrm{g}, \mathrm{h})$. 

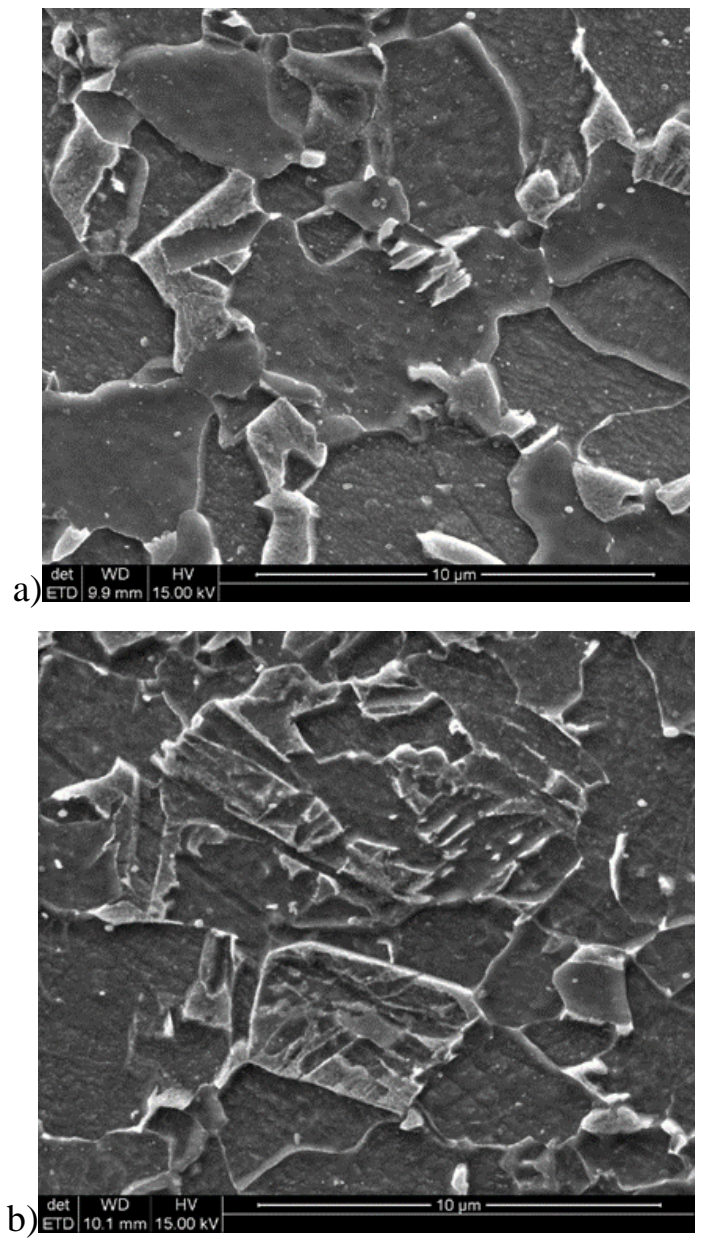

preaheating schedule iii. Preheating schedule ii resulted in about $40 \%$ of ferrite and combination of the granular bainite and martensite.
Fig. 3. Microstructure after preheating according to schedule $i$ and cooling at $25^{\circ} \mathrm{C} / \mathrm{s}(\mathrm{a}), 50^{\circ} \mathrm{C} / \mathrm{s}(\mathrm{b})$ and $140^{\circ} \mathrm{C} / \mathrm{s}(\mathrm{c})$.

Analysis of the micrographs shows that maximum cooling rate of $135^{\circ} \mathrm{C} / \mathrm{s}$ gives combination of ferrite, granular bainite and martensite. Predominantly martensitic microstructure was obtained for the preheating schedule iv (figure 5c). More ferrite and degenerated upper bainite was obtained for the
A decrease of the cooling rate leads to an increase of the ferrite volume fraction in the microstructure (figures $2 \mathrm{ab}, 3 \mathrm{ab}$ and $4 \mathrm{ab}$ ). For the cooling rate of $25^{\circ} \mathrm{C} / \mathrm{s}$ volume fraction is aroud $50 \%, 55 \%$ and $60 \%$ for the preaheating schedules ii, iii and iv, respectively. Recapitulating, the experiments have shown that typical multiphase microstructure was obtained for the preheating schedules iii and iv and for the cooling rate exceeding $50^{\circ} \mathrm{C} / \mathrm{s}$.
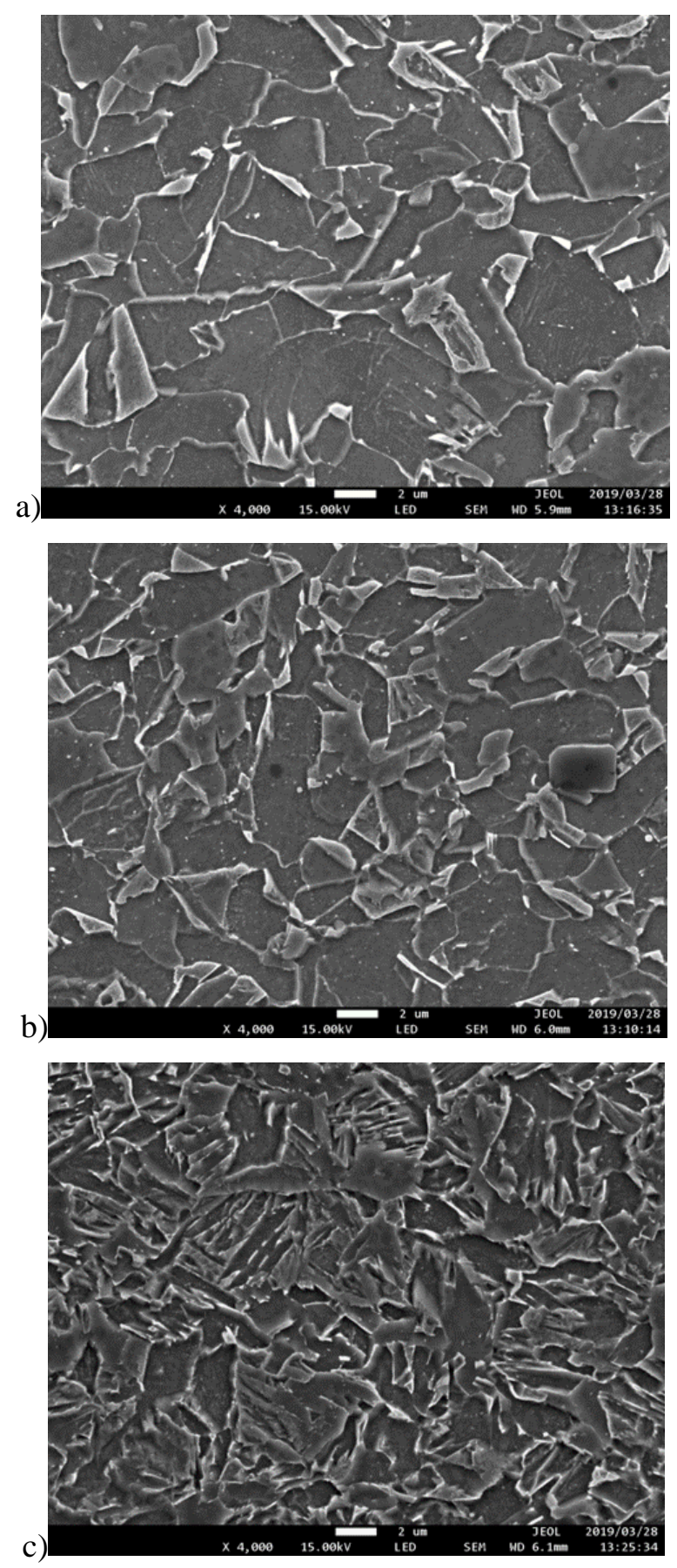

Fig. 4. Microstructure after preheating according to schedule iii and cooling at $25^{\circ} \mathrm{C} / \mathrm{s}(\mathrm{a}), 50^{\circ} \mathrm{C} / \mathrm{s}(\mathrm{b})$ and $140^{\circ} \mathrm{C} / \mathrm{s}(\mathrm{c})$. 

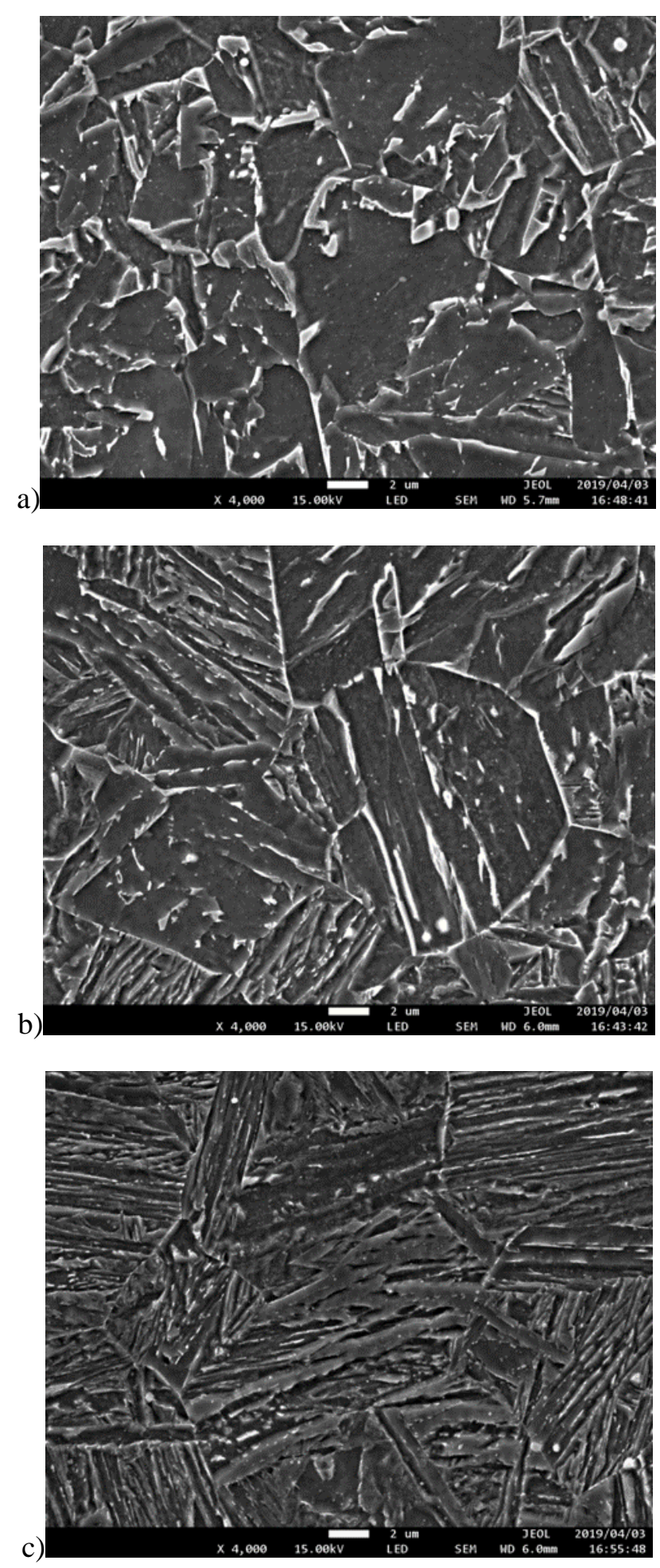

Fig. 5. Microstructure after preheating according to schedule iv and cooling at $25^{\circ} \mathrm{C} / \mathrm{s}(\mathrm{a}), 50^{\circ} \mathrm{C} / \mathrm{s}(\mathrm{b})$ and $140^{\circ} \mathrm{C} / \mathrm{s}(\mathrm{c})$.

Hardness of each sample after the test was measured, as well, and the results are presented in table 1 . Analysis of these results shows that reversed relation of the hardness on the preheating temperature was obtained for low cooling rates. It colud be also conclused that the selected chemical composition of the high strength steel allows to obtain similar mechanical properties for a wide range of the cooling rates.
Table 1. Hardness of the samples after various cooling rates.

\begin{tabular}{|c|c|c|c|}
\hline preheating & i & iii & iv \\
\hline $0.017^{\circ} \mathrm{C} / \mathrm{s}$ & 165 & 149 & 134 \\
\hline $0.1^{\circ} \mathrm{C} / \mathrm{s}$ & 184 & 163 & 149 \\
\hline $0.5^{\circ} \mathrm{C} / \mathrm{s}$ & 187 & 167 & 192 \\
\hline $1^{\circ} \mathrm{C} / \mathrm{s}$ & 190 & 176 & 201 \\
\hline $2^{\circ} \mathrm{C} / \mathrm{s}$ & 195 & 169 & 314 \\
\hline $5^{\circ} \mathrm{C} / \mathrm{s}$ & 196 & 193 & 223 \\
\hline $10^{\circ} \mathrm{C} / \mathrm{s}$ & 201 & 204 & 234 \\
\hline $25^{\circ} \mathrm{C} / \mathrm{s}$ & 206 & 229 & 249 \\
\hline $50^{\circ} \mathrm{C} / \mathrm{s}$ & 216 & 239 & 291 \\
\hline $135^{\circ} \mathrm{C} / \mathrm{s}$ & 243 & 288 & 328 \\
\hline
\end{tabular}

\section{MODELS}

\subsection{JMAK model}

The first phase transformation model is an upgrade of the JMAK (Johnson-Mehl_Avrami-Kolmogorov) equation. The numerical implementation of this model is described in (Pietrzyk \& Kuziak, 2012) and only main equations are repeated below. JMAK equation has the form:

$$
X=1-\exp \left(-k t^{n}\right)
$$

where: $X-$ volume fractions of a new phase, $n-\mathrm{Av}$ rami exponent, $k$ - coefficient.

The following upgrades of this equation were introduced in the present work (Pietrzyk et al., 2015):

- Avrami coefficient $n$ is assumed constant for each transformation and is the optimization variable assigned as $a_{4}, a_{16}$ and $a_{24}$ for ferritic, pearlitic and bainitic transformations, respectively.

- Coefficient $k$ was introduced as a function of temperature, as shown by Pietrzyk and Kuziak (2012). Modified Gauss function was used for the ferrite transformation (Donmay et al., 1996). Nose of this function is located at the temperature of maximum rate of the transformation. Exponential function was used for the bainite transformation (Pietrzyk et al., 2015, see equation (2)).

- Using Gauss function for $k_{f}$ does not require the incubation time. It is assumed that ferrite transformation begins when $5 \%$ of ferrite is predicted by equation (1). Equations (3) describe the incubation time for pearlite and bainite transformations.

- Calculations of carbon concentration in the austenite during both ferrite and bainite transformations were added. In consequence prediction of the retained austenite occurrence became possible.

- Relation of the incubation time and kinetics of transformation on the austenite grain size prior to transformation $\left(D_{\gamma}\right)$ was introduced. 
Coefficients $k$ for ferrite $\left(k_{f}\right)$, pearlite $\left(k_{p}\right)$ and bainite $\left(k_{b}\right)$ are defined as (Donnay et al., 1996):

$k_{f}=\frac{a_{5}}{D_{\gamma}} \exp \left[-\left(\frac{\left|T-A_{e 3}+\frac{400}{D_{\gamma}}-a_{6}\right|}{a_{7}}\right)^{a_{8}}\right]$

$k_{p}=\frac{a_{14}}{D_{\gamma}^{a_{16}}} \exp \left(a_{13}-a_{12} T\right)$

$k_{b}=\frac{a_{23}}{D_{\gamma}^{a_{29}}} \exp \left[\left(\frac{T-a_{21}}{a_{22}}\right)^{2}\right]$

As it has been mentioned, there is no incubation time for ferrite. The incubation times for pearlite $\left(\tau_{p}\right)$ and bainite $\left(\tau_{b}\right)$ are calculated as:

$$
\begin{gathered}
\tau_{P}=\frac{a_{9} D_{\gamma}^{a_{3}}}{\left(\mathrm{~A}_{e 1}-T\right)^{a_{11}}} \exp \left(\frac{a_{10}}{R T_{K}}\right) \\
\tau_{b}=\frac{a_{17} D_{\gamma}^{a_{30}}}{\left(B_{s}-T\right)^{a_{19}}} \exp \left(\frac{a_{18}}{R T_{K}}\right)
\end{gathered}
$$

Notation in equations (2) and (3): $T$ - temperature, in ${ }^{\circ} \mathrm{C}, T_{K}$ - temperature in $\mathrm{K}, R$ - gas constant. Start temperatures in ${ }^{\circ} \mathrm{C}$ for bainite $\left(B_{s}\right)$ is a variable in the identification procedure, $B_{s}=a_{20}$. Remaining equations describe start temperatures in ${ }^{\circ} \mathrm{C}$ for martensite $\left(M_{s}\right)$, volume fraction of martensite $\left(F_{m}\right)$ and equilibrium carbon concentrations at the austeniteferrite $\left(c_{\gamma \alpha}\right)$ and at the austenite-cementite $\left(c_{\gamma \beta}\right)$ boundaries:

$$
M_{s}=a_{25}-a_{26} c_{\gamma}
$$

$$
\begin{aligned}
& F_{m}=\left(1-F_{f}-F_{p}-F_{b}\right)\left\{1-\exp \left[-a_{27}\left(M_{s}-T\right)^{a_{28}}\right]\right\} \\
& c_{\gamma \alpha}=c_{\gamma \alpha 0}+c_{\gamma \alpha 1} T \\
& c_{\gamma \beta}=c_{\gamma \beta 0}+c_{\gamma \beta 1} T
\end{aligned}
$$

where: $F_{f}, F_{p}, F_{b}, F_{m},-$ volume fractions of ferrite, pearlite, bainite and martensite, respectively, calculated with respect to the whole volume of the material, $c_{\gamma \alpha 0}, c_{\gamma \alpha 1}, c_{\gamma \beta 0}, c_{\gamma \beta 1}$, - material parameters.

Equation (1) combined with the Scheil additivity rule (Scheil, 1935) allows to calculate changes of volume fraction of the new phase during transient state between the two equilibrium states. Equilibrium carbon concentrations $\left(c_{\gamma \alpha}\right)$ and $\left(c_{\gamma \beta}\right)$ are calculated from equations (6). Details of the numerical solution of this model are given in (Pietrzyk \& Kuziak, 2012; Pietrzyk et al., 2015). Accounting for changes of carbon concentration in the austenite during bainitic transformation is an important upgrade of the JMAK model. The current average carbon content in the austenite during bainitic transformation is described by the following equation:

$c_{\gamma}=\frac{\left[c_{0}-\left(F_{f}+\frac{F_{b}}{1-p}\right) c_{\alpha}\right]}{1-F_{f}-\frac{F_{b}}{1-p}}$

In equation (7) $p$ represents probability that a new platelet of the bainitic ferrite forms close to the existing one and its diffusion field is constrained by this neighbour. This probability is explained in (Katsamas and Haidemenopoulos, 2008). The whole model contains 30 coefficients, which are grouped in the vector a. These coefficients were determined using inverse analysis of the dilatometric data, see previous chapter for details.

\subsection{Upgrade of the Leblond equation}

The main assumption of Leblond (Leblond \& Devaux, 1984) was that the rate of the transformation is proportional to the distance from the equilibrium:

$\frac{d X}{d t}=c_{L}\left(X_{e q}-X\right)$

where: $X_{e q}$ - equilibrium volume fractions of a new phase in the current temperature, $c_{L}$-coefficient.

At this stage the model was developed for the ferrite transformation only. Typical responses of the material during isothermal transformations are similar to the response of the second order inertia term (Milenin et al., 2015), which is described by the second order differential equation with respect to time:

$B_{1}^{2} \frac{d^{2} X}{d t^{2}}+B_{2} \frac{d X}{d t}+X=\mathrm{f}(T)$

where: $B_{1}, B_{2}$ - time constants defined as functions of the temperature.

In the case of phase transformations the input signal is the temperature drop below $A_{e 3}$ and the output signal is the volume fraction of ferrite $(X)$. The right hand side in equation (9) is:

$\mathrm{f}(T)=\frac{F_{f T}}{F_{f \max }}$ 
where: $F_{f T}$ - equilibrium content of ferrite in steel at the current temperature $T, F_{\text {fmax }}$ - maximum volume fraction of ferrite in steel. These ferrite volume fractions are calculated from the following equations:

$$
F_{f T}=\frac{c_{\gamma \alpha}-c_{0}}{c_{\gamma \alpha}-c_{\alpha}} \quad F_{f \max }=1-\frac{\left(c-c_{\alpha}\right)}{\left(c_{\text {eut }}-c_{\alpha}\right)}
$$

where: c - carbon content in steel, c $\alpha$ - carbon content in ferrite, ceut - carbon content at eutectic, which is calculated as crossing point between lines $c \gamma \alpha$ and $c \gamma \beta$ defined by equations (6).

In order to describe phenomena of nucleation and growth, the two time constants in the model and were based on the mathematical description of the second order inertia term. Time constant $B_{1}$ is responsible for the delay of the response in the initial stage of transformation, therefore, it was correlated with the nucleation rate. Since nucleation rate directly depends on undercooling below $A_{e 3}$ temperature, the following equation was assumed

$$
B_{1}=a_{4} D_{\gamma}^{a_{1}} \exp \left[-a_{5}\left(A_{e 3}-T\right)\right]
$$

Time constant $B_{2}$ is responsible for the growth of the ferrite phase, so it was correlated with mobility of the interface and diffusion coefficient. Thus, it can be assumed that $B_{2}$ time constant can be presented in the form of modified inverse Gauss function with a nose at the temperature of maximum transformation rate (coefficient $a_{7}$ ). Finally, the following equation was proposed:

$$
B_{2}=a_{6} D_{\gamma}^{a_{2}} \exp \left[\left(\frac{a_{7}-T}{a_{8}}\right)^{2}\right]
$$

Equation (9) is solved using explicit finite difference method. This approach has following advantages comparing the upgrade of the JMAK equation (Milenin et al., 2019): i) it does not require an application of the additivity rule, ii) it works very well in varying temperatures, including processes characterised by increase/decrease of the temperature. In consequence, it allows to model metallurgical processes in real time.

Upgrade of the Leblond model is further referred to as CONT model. This model contains 5 coefficients in equations describing ferrite transformation. However, a change of the ferrite transformation model involved a change of the coefficients in the pearlite transformation model. Equations describing bainite and martensite transformation remained the same as in the JMAK model.

\subsection{Identification of the models}

Coefficients in equations (6) were determined first using TheromCalc with the SSOL4 data base. One of the work's objectives was to develop the model, which accounts for the elements segregation occurring during solidification of steel, which was described in numerous articles, from fundamental research on the reasons and conditions for ferrite and pearlite banding in strip (Grossterlinden et al., 1992) to the recent works dealing with various methods of treating this problem (Mo et al., 2005; Grajcar et al., 2012; Wang et al., 2015). In order to reach this objective, three chemical compositions were considered: the basic o, the area 1 with an increased content of $\mathrm{Mn}$ and the area 2 with a decreased content of Mn (table 2). Approximation of the ThermoCalc data yielded coefficients in equations (6) given in table 3 . Resulting part of the equilibrium diagram for the three compositions is shown in figure 6 .

Table 2. Chemical compositions of banded microstructure.

\begin{tabular}{|c|c|c|c|c|c|}
\hline Area & $\mathrm{Cr}$ & $\mathrm{Mn}$ & $\mathrm{Mo}$ & $\mathrm{Ni}$ & $\mathrm{Si}$ \\
\hline basic & 0.04 & 1.89 & 0.132 & 0.043 & 0.491 \\
\hline Area 1 & 0.28 & 2.3 & 0.5 & 0.10 & 0.49 \\
\hline Area 2 & 0.03 & 1.5 & 0.05 & 0.03 & 0.49 \\
\hline
\end{tabular}

Table 3. Coefficients in equations (6) for banded microstructure.

\begin{tabular}{|c|c|c|c|c|}
\hline Area & $c_{\gamma \alpha 0}$ & $c_{\gamma \alpha 1}$ & $c_{\gamma \beta 0}$ & $c_{\gamma \beta 1}$ \\
\hline basic & 5.1148 & -0.0061 & -1.05167 & 0.002415 \\
\hline Area 1 & 5.05 & -0.0061 & -1.1757 & 0.0025 \\
\hline Area 2 & 5.179 & -0.0062 & -1.16 & 0.0025 \\
\hline
\end{tabular}

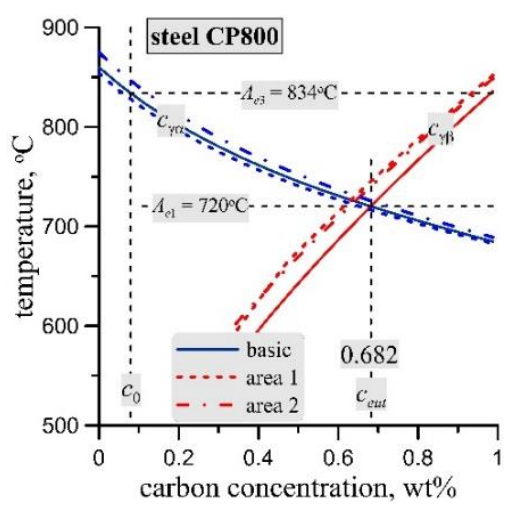

Fig. 6. Part of the equilibrium diagram (lines $c_{\gamma \alpha}$ in blue and $c_{\gamma \beta}$ in red) determined using ThermoCalc software for various areas in the investigated steel strip.

Details of the inverse algorithm which was applied to models identification are given in (Bachniak et al., 2017). Particle Swarm Optimization (PSO) method was used in the inverse analysis. Verification and validation of both models for a variety of steels is shown in (Pietrzyk et al., 2015; Milenin et al., 2015). Values of coefficients determined for the investigated steel are given in table 4 for the JMAK model and in table 5 for the CONT model. 
Table 4. Coefficients in the JMAK model for the investigated steel.

\begin{tabular}{|c|c|c|c|c|c|c|c|c|c|c|c|c|c|}
\hline$a_{3}$ & $a_{4}$ & $a_{5}$ & $a_{6}$ & $a_{7}$ & $a_{8}$ & $a_{9}$ & $a_{10}$ & $a_{11}$ & $a_{12}$ & $a_{13}$ & $a_{14}$ & $a_{15}$ & $a_{16}$ \\
\hline 1.931 & 1.243 & 2.211 & 361.8 & 94.5 & 2.137 & 4707.2 & 62.83 & 3.085 & 394.4 & 15.77 & 0.808 & 0.0002 & 1.755 \\
\hline$a_{17}$ & $a_{18}$ & $a_{19}$ & $a_{20}$ & $a_{21}$ & $a_{22}$ & $a_{23}$ & $a_{24}$ & $a_{25}$ & $a_{26}$ & $a_{27}$ & $a_{28}$ & $a_{29}$ & $a_{30}$ \\
\hline 3.318 & 0.139 & 1.814 & 567.2 & 541.5 & 29.44 & 0.503 & 0.496 & 501.7 & 0 & 0.011 & 1 & 0.261 & 1.684 \\
\hline
\end{tabular}

Table 5. Coefficients in the CONT model for the investigated steel.

\begin{tabular}{|c|c|c|c|c|c|c|c|c|c|c|c|c|c|c|}
\hline$a_{1}$ & $a_{2}$ & $a_{3}$ & $a_{4}$ & $a_{5}$ & $a_{6}$ & $a_{7}$ & $a_{8}$ & $a_{9}$ & $a_{10}$ & $a_{11}$ & $a_{12}$ & $a_{13}$ & $a_{14}$ & $a_{15}$ \\
\hline 3.79 & 0.002 & 2.99 & 0.323 & 0.032 & 3.0 & 421.5 & 136.7 & 5862.6 & 34.6 & 2.67 & 2 & 3.026 & 0.131 & 0.41 \\
\hline$a_{16}$ & $a_{17}$ & $a_{18}$ & $a_{19}$ & $a_{20}$ & $a_{21}$ & $a_{22}$ & $a_{23}$ & $a_{24}$ & $a_{25}$ & $a_{26}$ & $a_{27}$ & $a_{28}$ & $a_{29}$ & $a_{30}$ \\
\hline 0.369 & 0.009 & 6.192 & $3.1 \times 10^{-6}$ & 562.9 & 541.9 & 29.5 & 0.22 & 1.441 & 503.1 & 0.003 & 0.011 & 1 & 2.712 & 0.927 \\
\hline
\end{tabular}

Models with optimal coefficients were verified and the results for the JMAK model are presented in figure 7 in the form of comparison of the measured and calculated start and end temperatures of transformation. As far as temperatures of phase transformations are considered, reasonably good accuracy of both models was obtained. Similar good agreement was obtained for the CONT model.

\section{NUMERICAL TESTS}

Three sets of numerical tests were performed. The first composed predictions of the phase composition for various constant cooling rates. The second composed simulations of various cooling strategies. The objective was to validate the models and to evaluate their predictive capabilities. In the third set of the phase transformation models were implemented in the FE program and simulations of the industrial laminar cooling and coiling were carried out.

\subsection{Constant cooling rate.}

Calculations of volume fractions of phases for various cooling rates were performed and the selected results obtained from the two models are presented in figure 8 . The models give similar predictions for lower cooling rates and some discrepancies were observed above $10^{\circ} \mathrm{C} / \mathrm{s}$. All further results are opresented for the JMAK model only.

Callculations of the phase composition for various cooling rates and for the banded microstructure were performed next and the results are presented in figure 9. In the areas of increased manganese and molybdenum content slight deacrease of the ferrite volume fraction is observed. Much stronger effect was observed for the area 2 with decreased content of the manganese and molybdenum, where significant decrease of the ferrite volume fraction and increase of the bainite volume fraction was observed. Marteniste in this area occurred at much lower cooling rates.
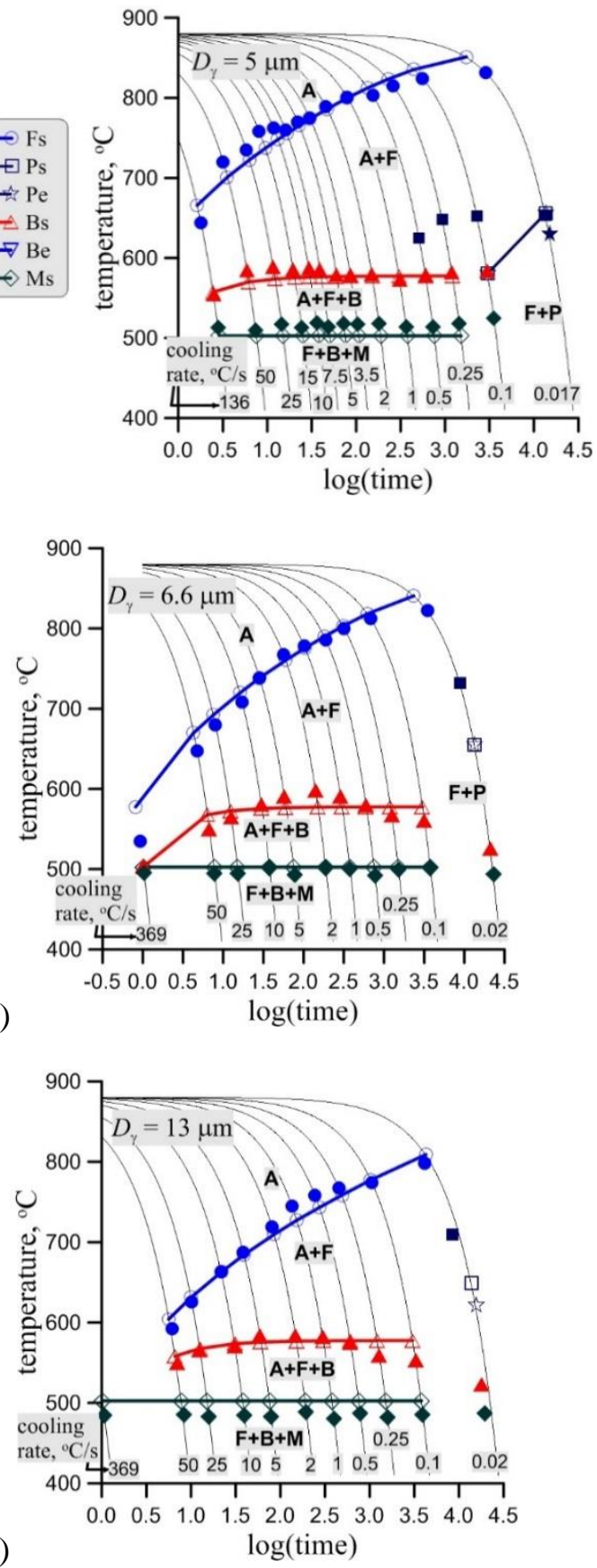

Fig. 7. Comparison of the transformation start and end temperatures calculated by the JMAK model (open symbols) and measured in the dilatometric tests (filled symbols) for the preheating schedules $i(a)$, iii $(b)$ and iv $(c)$. 


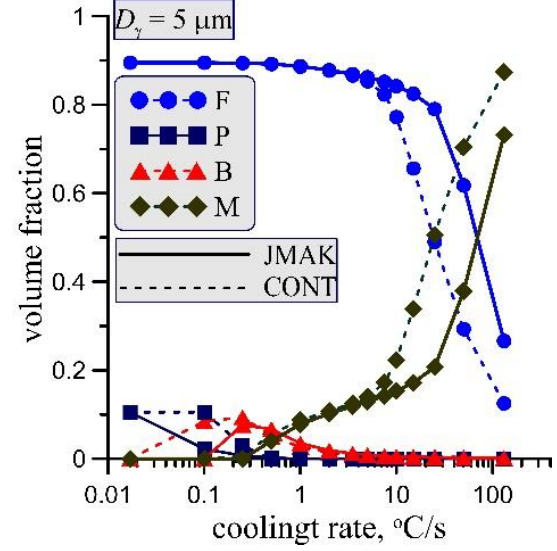

Fig. 8. Calculated volume fractions of phases for various cooling rates and for the austenite grain size $5 \mu \mathrm{m}$.

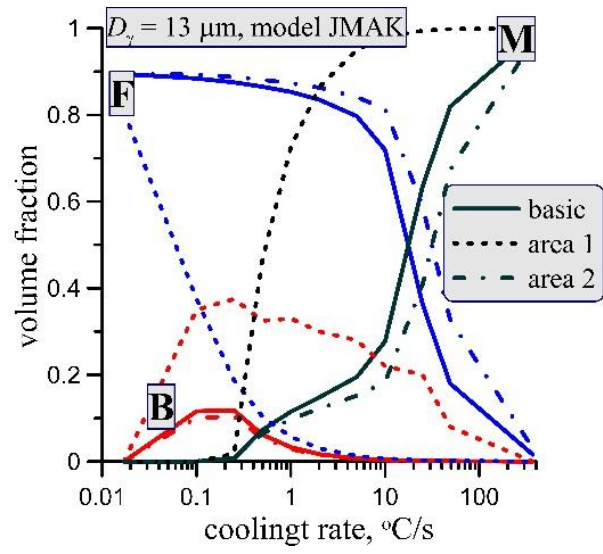

Fig. 9. Calculated volume fractions of phases for various cooling rates and for various areas in the investigated steel strip.

Pearlite occurred at the lowest cooling rates only and volume fraction of perlite was small, therefore, this structural component is not presented in figure 9 .

\subsection{Validation of the models}

Further numerical tests composed simulations of various cooling strategies. Calculations using both models were performed, however, since the predictions were similar, the results for the JMAK model only are presented.

The cooling schedules, which were considered, composed of fast cooling $\left(50^{\circ} \mathrm{C} / \mathrm{s}\right)$ followed by slow cooling $\left(0.2^{\circ} \mathrm{C} / \mathrm{s}\right)$ and again fast cooling $\left(50^{\circ} \mathrm{C} / \mathrm{s}\right)$. The first set of the tests was focused on an evaluation of the effect of the temperature, at which slow cooling begins. The time of the slow cooling was $25 \mathrm{~s}$. The results of these tests are presented in figure 10. It is seen that for tha basic composition and for the area 2 ferrite is dominating at temperatures above $570^{\circ} \mathrm{C}$ and martensite is dominating below this temperature. Maximum volume fraction of the bainite was obtained for the temperatures of $540^{\circ} \mathrm{C}$. For the composition of the area 1 (increased content of $\mathrm{Mn}, \mathrm{Cr}$ and Mo) ferritic transformation was significantly slowed down and martensite was dominating in the microstructure for all temperatures. Maximum volume fraction of the bainite was obtained at the slightly larger temperature of $560^{\circ} \mathrm{C}$.

In the second set of the tests the effect of the time of the slow cooling was investigated. These results are presented in figure 11 for the temperature of the slow cooling equal $540^{\circ} \mathrm{C}$. In all cases the volume fraction of the bainite increases and the volume fraction of the martensite decreases with increasing time of the slow cooling. The largest volume fraction of the bainite was obtained for the area 1 and the smallest for the area 2.
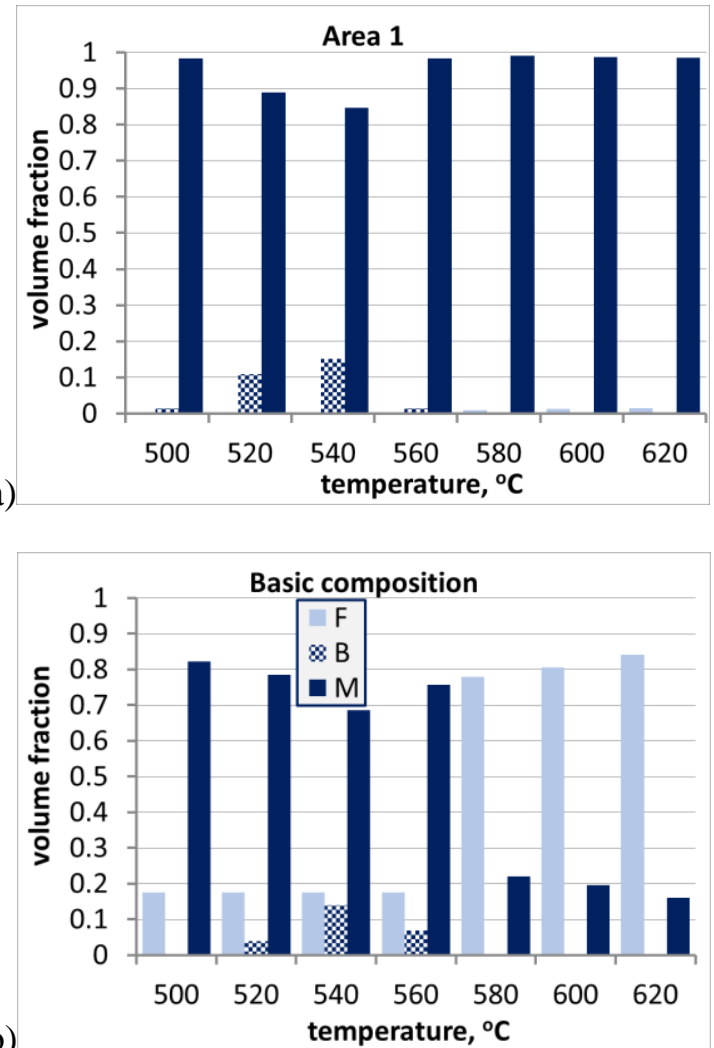

b)

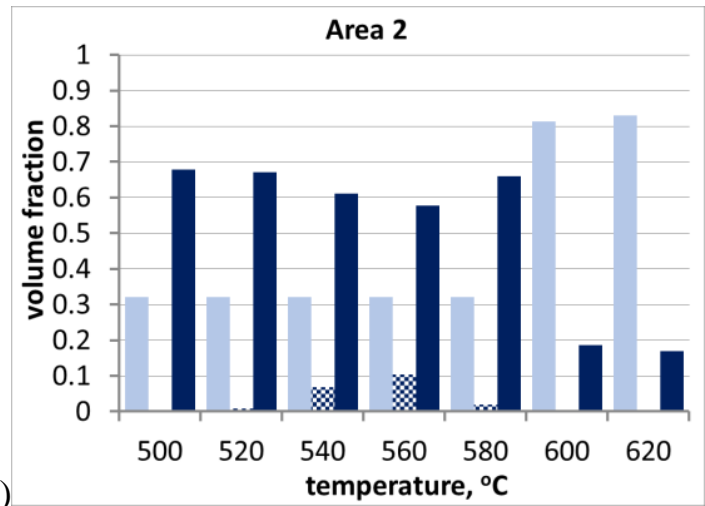

Fig. 10. Effect of the temperature at the beginning of the slow cooling on the volume fractions of phases calculated for the investigated cooling schedules a) area 1, b) basic composition, $c$ ) area 2. Time of the slow cooling $25 \mathrm{~s}$. 
Analysis of the results of all the numerical tests leads to a conclusion that, comparing to the basic chemical compositions of the steel, an increase of the $\mathrm{Mn}, \mathrm{Cr}$ and Mo (area 1) leads bainitic-martensitic microstructures for higher cooling rates. In the area with decreased content of the $\mathrm{Mn}, \mathrm{Cr}$ and Mo (area 2) predominantly ferrite and martensite were observed.
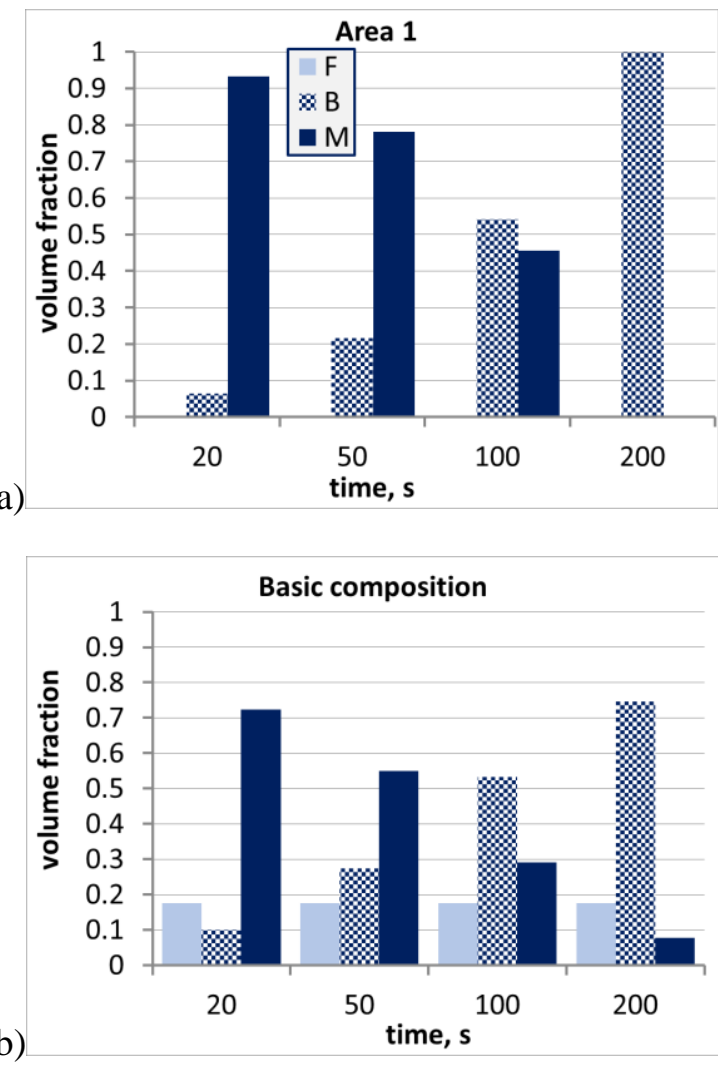

b)

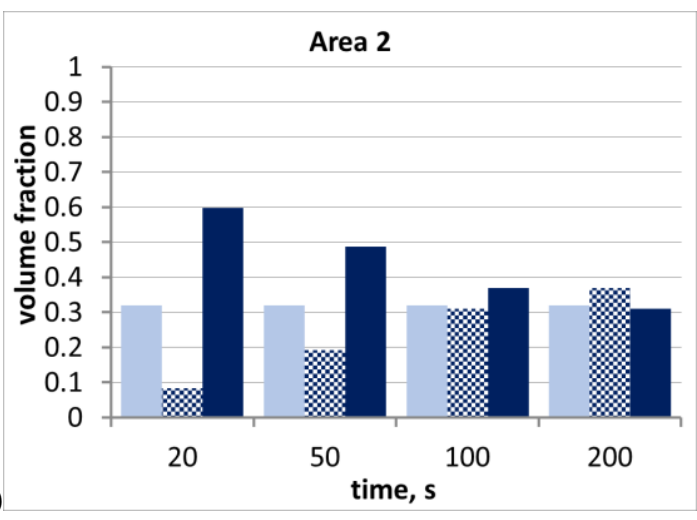

Fig. 11. Effect of the time of the slow cooling on the volume fractions of phases calculated for the investigated cooling schedules: a) area 1, b) basic composition, c) area 2. Temperature at the beginning of the slow cooling $540^{\circ} \mathrm{C}$.

\subsection{Laminar cooling and coiling processes}

Finite element model of the laminar cooling and coiling processes is described in (Pietrzyk et al., 2014). Phase transformation models described in the present paper were implemented into the FE code and current, local changes of the temperature were used in the calculations of the kinetics of transformation. As a feedback the heat due to recalescence was returned to the FE program and was accounted for in the calculation of the temperature distribution.

The rolling process parameters are given in (Rauch et al., 2019). The following entry parameters for the laminar cooling were assumes: strip velocity 7 $\mathrm{m} / \mathrm{s}$, strip thickness $4 \mathrm{~mm}$ and end of rolling temperature $910^{\circ} \mathrm{C}$. The laminar cooling system was composed of two sections with 40 water boxes in each section and with $20 \mathrm{~m}$ distance between the sections (Pietrzyk et al., 2014; Rauch et al., 2019). The coiling temperatures (CT) between $450^{\circ} \mathrm{C}$ and $650^{\circ} \mathrm{C}$ were considered. The cooling sequence in the first section was intensive for all coiling temperatures. The cooling sequence in the second section was adjusted to obtain required coiling temperature. Calculated time temperature profiles for various coiling temperatures are shown in figure 12 .

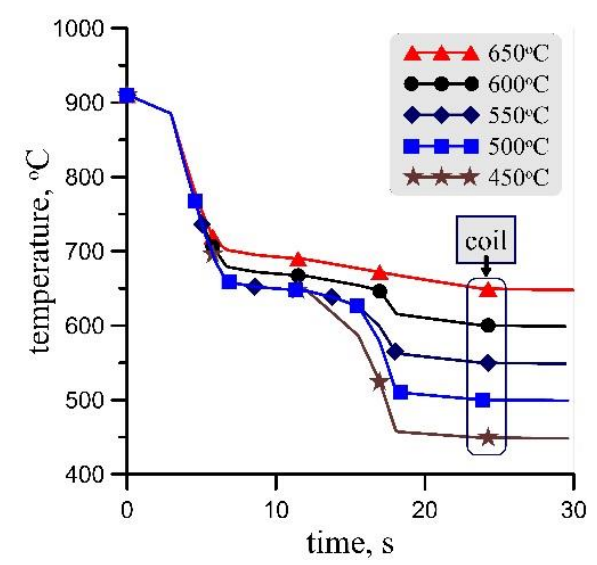

Fig. 12. Calculated time temperature profiles for various coiling temperatures.

Calculated phase composition after cooling accounting for the element's segregation is shown in figure 13. Results in this figure confirmed general tendency as far as the effect of elements' segregation during solidification of steel is considered. In the areas with increased content of $\mathrm{Mn}, \mathrm{Cr}$ and $\mathrm{Mo}$ (area 1) bainite (higher CT) and martensite (lower CT) were dominating in the microstructure. Contrary, in the area with decreased content of $\mathrm{Mn}, \mathrm{Cr}$ and $\mathrm{Mo}$ (area 2) predominantly ferrite was predicted with some bainite at higher CT and martensite at lower CT. Typical complex phase microstructures were obtained for the coiling temperature in the range $500-550^{\circ} \mathrm{C}$. 


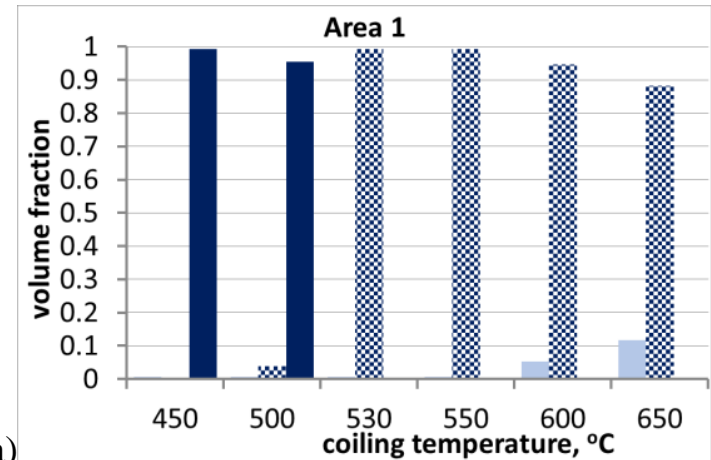

a)
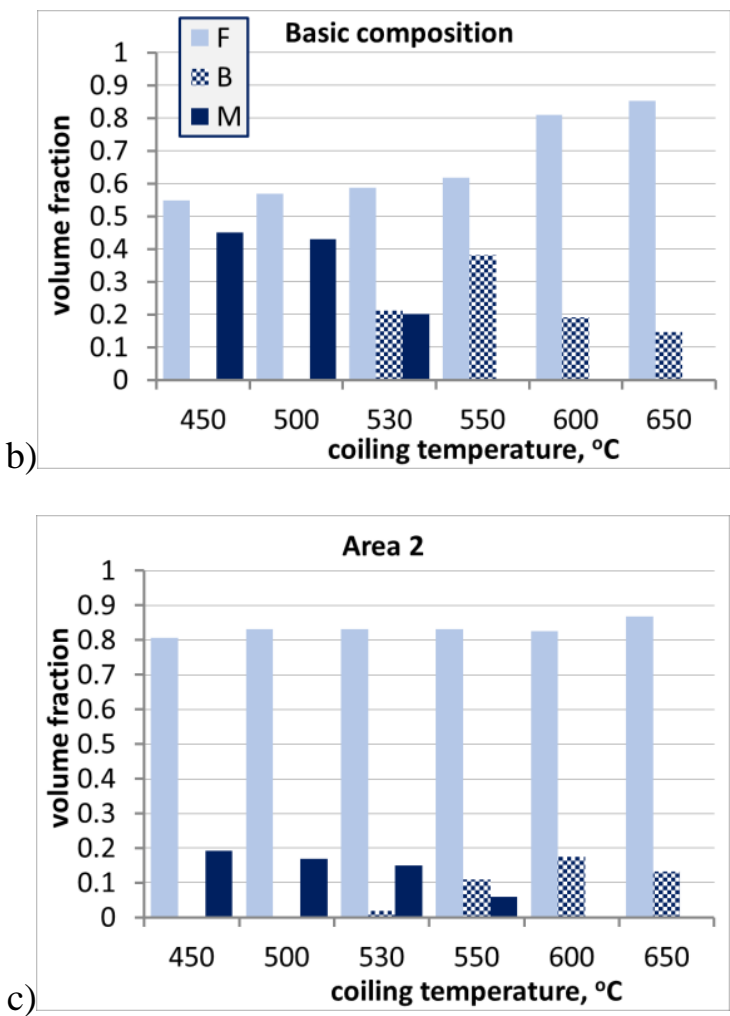

Fig. 13. Effect of the time of the coiling temperature on the volume fractions of phases: a) area $1, b$ ) basic composition, $c$ ) area 2. Temperature at the beginning of the slow cooling $540^{\circ} \mathrm{C}$.

\section{CONCLUSIONS}

Two fast models of phase transformation for steels were identified and optimal coefficients in these models were determined. Dilatometric tests for various cooling rates after preheating at various temperature were performed and the coefficients in the models were identified. Numerical tests were carried out and the following conclusions were drawn:

- Due to small austenite grain size prior to transformations the ferrite transformation was fast. Mainly ferritic microstructure was obtained for the cooling rates below $10^{\circ} \mathrm{C} / \mathrm{s}$.

- Since ferrite was a dominating phase, the hardness of the samples was low in the range HV 165-243.

- Analysis of the micrographs showed that predominantly martensitic microstructure was obtained for preheating at $1100^{\circ} \mathrm{C}$ and high cooling rates. Decrease of the preheating temperature led to more ferrite and degenerated bainite in the microstructure. A decrease of the cooling rate leads to further increase of the ferrite volume fraction.

- The experiments have shown that typical multiphase microstructure was obtained for higher preheating temperatures and for the 3 step cooling cycle.

- The effect of variations of the chemical composition due to banded microstructure was investigated. In the areas with increased content of Mn, $\mathrm{Cr}$ and Mo (area 1) bainite and martensite were dominating in the microstructure for higher cooling rates. Contrary, in the area with decreased content of $\mathrm{Mn}, \mathrm{Cr}$ and Mo (area 2) predominantly ferrite and martensite were observed.

- The phase transformation models with optimal coefficients reproduce properly behaviour of the investigated steel during cooling. Numerical tests for complex cooling schedules confirmed good predictive capabilities of the models.

- Simulations of the laminar cooling and coiling confirmed general tendency as far as the effect of elements' segregation during solidification of steel is considered.

\section{ACKNOWLEDGMENTS}

Work within the Beethoven project financed by DFG in Germany (project no. BL 402/46-1) and NCN in Poland (project no. 2016/23/G/ST5/04059).

\section{REFERENCES}

Bachniak, D., Rauch, Ł, Pietrzyk, M., Kusiak, J., 2017, Selection of the optimization method for identification of phase transformation models for steels, Materials and Manufacturing Processes, 32, 1248-1259.

Bhadeshia, H.K.D.H., 2001, Bainite in steels: transformations, microstructure and properties, 2nd ed., IOM Communications, London.

Donnay, B., Herman, J.C., Leroy, V., Lotter, U., Grossterlinden, R., 1996, Microstructure evolution of C-Mn Steels in the hot deformation process: The STRIPCAM model, Proc. 2nd Conf. Modelling of Metal Rolling Processes, eds, Beynon, J.H., Ingham, P., Teichert, H., Waterson, K., Pircher, H., London, 23-35.

Grajcar, A., Kamińska, M., Opiela, M., Skrzypczyk, P., Grzegorczyk, B., Kalinowska-Ozgowicz, E., 2012, Segregation of alloying elements in thermomechanically rolled mediumMn multiphase steels, Journal of Achievements in Materials and Manufacturing Engineering, 55, 256-264.

Grossterlinden, R., Kawalla, R., Lotter, U., Pircher, H., 1992, Formation of pearlitic banded structures in ferritic-pearlitic steels, steel research, 63, 331-336. 
Farivar, H., Richter, S., Hans, M., Schwedt, A., Prahl, U., Bleck, W., 2018, Experimental quantification of carbon gradients in martensite and its multi-scale effects in a DP steel, Materials Science and Engineering A, 718, 250-259.

Fonstein, N., 2015, Complex Phase Steels. Advanced High Strength Sheet Steels. Springer, Cham, 241-258.

Karelova, A., Krempaszky, C., Werner, E., Tsipouridis, P., Hebesberger, T., Pichler, A., 2009, Hole expansion of dualphase and complex-phase AHS steels - effect of edge conditions, Steel Research International, 80, 71-77.

Katsamas, A.I., Haidemenopoulos G.N., 2008, A semi-empirical model for the evolution of retained austenite via bainitic transformation in multiphase TRIP steels, Steel Research International, 79, 875-884.

Kuziak, R., Kawalla, R., Waengler, S., 2008, Advanced high strength steels for automotive industry, Archives of Civil and Mechanical Engineering, 8, 103-17.

Leblond, J.B., Devaux, J., 1984, A new kinetic model for anisothermal metallurgical transformations in steel including effect of austenite grain size, Acta Metallurgica, 32, 137-146.

Maity, S.K., Kawalla, R., 2011, Ultrahigh strength steel: development of mechanical properties through controlled cooling, Chapter 13 in: Heat transfer - engineering applications, ed. Vikhrenko, V., InTech, Rijeka, Shanghai, 309-336.

Milenin, I., Pernach, M., Pietrzyk, M., 2015, Application of the control theory for modelling austenite-ferrite phase transformation in steels, Computer Methods in Materials Science, 15, 327-335.

Milenin, I., Kuziak, R., Rauch, Ł., Pietrzyk, M., 2019, Model of phase transformations in steels subject to heating-cooling thermal cycles in continuous annealing line, Canadian Metallurgical Quarterly, (in press).

Mo, C.L., Zhang, Y.T., Li, D.Z., Li, Y.Y., 2005, Microstructural banding in the center of hot rolling strip, Acta Metallurgica Sinica, 18, 664-668

Pietrzyk, M., Kuziak, R., 2012, Modelling phase transformations in steel, in: Microstructure evolution in metal forming processes, (eds), Lin J., Balint D., Pietrzyk M., Woodhead Publishing, Oxford, 145-179.

Pietrzyk, M., Kusiak, J., Kuziak, R., Madej, Ł., Szeliga, D., Gołąb, R., 2014, Conventional and multiscale modelling of microstructure evolution during laminar cooling of DP steel strips, Metallurgical and Materials Transactions B, 46B, 497-506.

Pietrzyk, M., Madej, Ł., Rauch, Ł., Szeliga, D., 2015, Computational Materials Engineering: Achieving high accuracy and efficiency in metals processing simulations, ButterworthHeinemann, Elsevier, Amsterdam.

Rauch, Ł., Bzowski, K., Kuziak, R., Uranga, P., Gutierrez, I., Isasti, N., Jacolot, R., Kitowski, J., Pietrzyk, M., 2019, Computer-integrated platform for automatic, flexible, and optimal multivariable design of a hot strip rolling technology using advanced multiphase steels, Metals, 9, 737; doi:10.3390/met9070737

Ryde, L., Lyytinen, O., Peura, P., Titova, M., Granbom, Y.V., Hebesberger, T., 2012, Cold-rolled complex-phase (CP) steel grades with optimized bendability, stretch-flangeability and anisotropy (CP-Steels), European Commission, RFCS project report, RFSR-CT-2006-00021, Luxemburg.

Scheil, E., 1935, Anlaufzeit der Austenitumwandlung, Archiv für Eissenhüttenwesen, 12, 565-567.

Szeliga, D., Chang, Y., Bleck, W., Pietrzyk, M., 2019, Evaluation of using distribution functions for mean field modelling of multiphase steels, Procedia Manufacturing, 27, 72-77.
Thomser, C., Uthaisangsuk, V., Bleck, W., 2009, Influence of martensite distribution on the mechanical properties of dual phase steels: experiments and simulation, Steel Research International, 80, 582-587.

Vajragupta, N., Wechsuwanmanee, P., Lian, J., Sharaf, M., Münstermann, S., Ma, A., Hartmaier, A., Bleck, W., 2014, The modeling scheme to evaluate the influence of microstructure features on microcrack formation of DP-steel: The artificial microstructure model and its application to predict the strain hardening behavior, Computational Materials Science, 94, 198-213.

Wang, M., Xu, G., Zhang, Y., Wang, L., 2015, Effect of heat treatment on the banded structure of the hot rolled 30CrMo steel, in: Proc. Conf. Material Science and Engineering ICMSE, ed., Chen, P., CRC Press, Guangzhou, Guangdong, 91-94.

Weiß-Borkowski, N., Lian, J., Camberg, A., Tröster, T., Münstermann, S., Bleck, W., Gese, H., Richter, H., 2018, Forming limit curves of DP600 determined in high-speed Nakajima tests and predicted by two different strain-rate-sensitive models, AIP Conference Proceedings, 1960, 150017.

\section{SZYBKIE MODELE PRZEMIAN FAZOWYCH PODCZAS CHLODZENIA WSTEPNIE WYŻARZONYCH STALI WIELOFAZOWYCH}

\section{Streszczenie}

W artykule opisano doświadczalną i numeryczną analizę przemian fazowych w wybranej stali o podwyższonej wytrzymałości. Próby dylatometryczne wykonano w szerokim zakresie prędkości chłodzenia. Rozważono dwa modele wykorzystujące metodę średniego pola. Pierwszym modelem była zmodernizowana wersja modelu JMAK (Johnson-Mehl-Avrami-Kolmogorov). Drugim modelem było rozwinięcie równania Leblonda. Przeprowadzono identyfikację modeli wykorzystując rozwiązanie odwrotne dla prób dylatometrycznych. W celu walidacji modeli wykonano symulacje różnych schematów chłodzenia. Wyznaczono skład fazowy dla tych schematów. Następnie oszacowano wahania składu chemicznego w badanej stali i wykorzystano opracowane modele do określenie wpływu segregacji pierwiastków podczas krzepnięcia stali na powstawanie pasm martenzytu/bainitu.

Received: October 28, 2019. Received in a revised form: December 12, 2019. Accepted: December 22, 2019. 